\title{
Total artificial heart in patients with post-infarction ventricular septal defect
}

\author{
Igor D. Gregoric $c^{1,2,3}$ \\ ${ }^{1}$ Surgical Division, ${ }^{2}$ Research Division, Center for Advanced Heart Failure, Memorial Hermann Hospital Heart \& Vascular Institute, Houston, TX, \\ USA; ${ }^{3}$ Department of Advanced Cardiopulmonary Therapies and Transplantation, University of Texas Health Science Center at Houston, Houston, \\ TX, USA \\ Correspondence to: Igor D. Gregoric, MD. Center for Advanced Heart Failure, Memorial Hermann Hospital Heart \& Vascular Institute, Houston, \\ TX 77030, USA. Email: igregoric@hotmail.com.
}

Submitted Nov 26, 2019. Accepted for publication Jan 10, 2020.

doi: 10.21037/acs.2020.01.04

View this article at: http://dx.doi.org/10.21037/acs.2020.01.04

Ventricular septal defect (VSD) following acute myocardial infarction (AMI) is associated with very high mortality regardless of the treatment approach. Depending on the extent of infarction and size of the septal rupture, left-toright shunting increases pulmonary blood flow, systemic blood flow is decreased, and cardiac function is severely compromised. Conservative medical therapy has dismal results, with a mortality rate nearing $90 \%$, while the overall rate for patients undergoing surgical repair is $43 \%$, with these patients having the worst outcomes of all cardiac surgical procedures $(1,2)$. Experience with percutaneous transcatheter closure of post-AMI VSD is limited to small case series, with reports of mortality as high as $65 \%$ $(3,4)$. In cases of small VSD with stable hemodynamics, percutaneous closure is a suitable treatment option.

An absence of large clinical trials or registry data means the optimal approach and timing of treatment remains controversial. In hemodynamically stable patients, there is equipoise for delayed surgical repair or percutaneous device placement to allow for collagen replacement of necrotic myocytes and strengthening of friable tissue that is needed for device anchoring or suture line strength. Stable patients without organ failure may be carefully monitored and safely undergo delayed closure. In the overall population undergoing surgical VSD repair, there is a significant survival advantage in delaying surgery for at least seven days (1). However, during the waiting period, the risk is high for developing cardiogenic shock or expansion of the VSD to the point of being inoperable (5).

Early development of cardiogenic shock following
$\mathrm{AMI} / \mathrm{VSD}$ is common and the mortality rate approaches 90\% (6). Early coronary reperfusion and mechanical circulatory support (MCS) may stabilize hemodynamics, minimize shunting, help preserve organ function, and limit VSD expansion. A staged approach in treating patients with post-AMI VSD who also present with cardiogenic shock and pulmonary edema may improve outcomes in select patients (5) MCS with a percutaneous device that directly unloads the left ventricle is necessary to decrease left-to-right shunting and myocardial wall stress. If coronary revascularization is required, percutaneous coronary stent placement should be performed after MCS is initiated. Stabilized patients may be extubated, and inotropic medications are reduced while the infarcted area stabilizes. After approximately one week, transthoracic or transesophageal echocardiography is used to reassess the size and location of the VSD. If the VSD diameter is $\leq 2.5 \mathrm{~cm}$, adequate septal margin exists for device anchoring with adequately thick myocardial free wall, the position of the VSD is central rather than apical, and there is no proximity to the aortic valve, percutaneous closure is the preferred choice of treatment. If percutaneous coronary revascularization or VSD repair is not feasible, surgical repair and coronary artery bypass should be performed.

Patients with severe refractory cardiogenic shock and biventricular failure may require durable MCS or heart transplantation (7). Although the implantable left ventricular assist device (LVAD) has been successfully used as a bridge to transplant in patients with post-AMI VSD (8), placement of the LVAD inflow conduit may be very difficult 
if the apical myocardium is extensively necrotic. Inflow placement through friable apical myocardium may result in catastrophic bleeding complications. In cases of severe valvular insufficiency, LVAD function may be compromised and device support may be inadequate. The total artificial heart (TAH) may be a suitable treatment option for select patients following AMI/VSD with refractory cardiogenic shock. These TAH candidates have a very low probability of success with surgical repair and percutaneous closure, yet they are suitable for heart transplantation. TAH implantation may be indicated for patients who are not responding to percutaneous mechanical support and are not candidates for surgical repair or percutaneous closure due to size and location of the VSD or who have other structural complications.

Post-AMI VSD with severe refractory cardiogenic shock is uncommon yet is a very challenging clinical scenario. Reports are scarce on the clinical use of the biventricular assist device or TAH, but have been demonstrated to have a positive outcome $(7,9,10)$. Early TAH implantation can obviate the structural heart complications that lead to severe refractory cardiogenic shock and death. In patients with preserved neurologic and end-organ function, the TAH, as a bridge to heart transplant, offers the possibility of longterm survival following this devastating problem.

\section{Acknowledgments}

None.

\section{Footnote}

Conflicts of Interest: The author has no conflicts of interest to declare.

\section{References}

1. Arnaoutakis GJ, Zhao Y, George TJ, et al. Surgical repair of ventricular septal defect after myocardial infarction: outcomes from the Society of Thoracic Surgeons National

Cite this article as: Gregoric ID. Total artificial heart in patients with post-infarction ventricular septal defect. Ann Cardiothorac Surg 2020;9(2):116-117. doi: 10.21037/ acs.2020.01.04
Database. Ann Thorac Surg 2012;94:436-43; discussion 443-4.

2. Crenshaw BS, Granger CB, Birnbaum Y, et al. Risk factors, angiographic patterns, and outcomes in patients with ventricular septal defect complicating acute myocardial infarction. GUSTO-I (Global Utilization of Streptokinase and TPA for Occluded Coronary Arteries) Trial Investigators. Circulation 2000;101:27-32.

3. Maltais S, Ibrahim R, Basmadjian AJ, et al. Postinfarction ventricular septal defects: towards a new treatment algorithm? Ann Thorac Surg 2009;87:687-92.

4. Thiele H, Kaulfersch C, Daehnert I, et al. Immediate primary transcatheter closure of postinfarction ventricular septal defects. Eur Heart J 2009;30:81-8.

5. Gregoric ID, Kar B, Mesar T, et al. Perioperative use of TandemHeart percutaneous ventricular assist device in surgical repair of postinfarction ventricular septal defect. ASAIO J 2014;60:529-32.

6. Menon V, Webb JG, Hillis LD, et al. Outcome and profile of ventricular septal rupture with cardiogenic shock after myocardial infarction: a report from the SHOCK Trial Registry. SHould we emergently revascularize Occluded Coronaries in cardiogenic shocK? J Am Coll Cardiol 2000;36:1110-6.

7. Ashfaq A, Jaroszewski DE, Pajaro OE, et al. The role of the total artificial heart in the treatment of post-myocardial infarction ventricular septal defect. J Thorac Cardiovasc Surg 2013;145:e25-6.

8. Faber C, McCarthy PM, Smedira NG, et al. Implantable left ventricular assist device for patients with postinfarction ventricular septal defect. J Thorac Cardiovasc Surg 2002;124:400-1.

9. Conradi L, Treede H, Brickwedel J, et al. Use of initial biventricular mechanical support in a case of postinfarction ventricular septal rupture as a bridge to surgery. Ann Thorac Surg 2009;87:e37-9.

10. Knezevic I, Jelenc M, Danojevic N, et al. Use of a totally artificial heart for a complex postinfarction ventricular septal defect. Heart Surg Forum 2013;16:E155-7. 